\title{
Determination of optimum wave reflection of seawalls via experimental modeling
}

\author{
K. Nassar \& A. Negm \\ Environmental Engineering Department, School of Energy and Environmental Engineering, Egypt-Japan \\ University of Science and Technology, E-JUST, P.O.Box 179, New Borg Al-Arab City, Postal Code 21934, \\ Alexandria,Egypt.Karim.nassar@ejust.edu.com,negm@ejust.edu.eg
}

\begin{abstract}
This paper presents and discusses the results of experimental investigations using both vertical and sloping seawalls configurations to determine the optimal wave reflection characteristics of seawalls for protecting beaches against erosion under a variety of hydrodynamic conditions. The different experiments include both of rectangular or triangular serrated blocks and slotted seawalls with or without triangular serrations as energy dissipaters. The linear wave theory is utilized. Moreover, the Dalrymple method is considered to predict the ordinates of the resultant standing wave due to the partial wave reflection. The study shows that the usage of slotted seawall with triangular serrations is superior compared to the other suggested energy dissipaters in reducing wave reflection whenever the waves become longer. The findings of the present investigation could be applied to optimize the design criteria of shore protection structures.
\end{abstract}

\section{INTRODUCTION}

Seawalls are constructed parallel to the coastline to provide a great defense against flooding of coastal low-land areas and to protect the shore from excessive erosion while also immobilizing the sand of the adjacent beach. To properly design seawalls detailed information is required on various wave hydrodynamics, configuration of the area to be protected and degree of severity. Number of theoretical and experimental studies on different hydrodynamic aspects on vertical as well as sloped seawalls is reported in the literature.

(Chen et al. 2006) presented numerical solutions for the wave reflection from submerged porous structures in front of the impermeable vertical seawall. (Lin \& Karunarathna 2007) studied the solitary wave interaction with fully emerged rectangular porous seawalls by using a two-dimensional numerical model. (Zanuttigh \& van der Meer 2008) developed a new formula using a large experimental data of the reflection coefficients for permeable and impermeable seawalls. (Theocharis et al. 2011) investigated experimentally a new type of wave absorbing quay-wall with a partial wave chamber containing a rock-armored slope. The wave reflection characteristics of a porous seawall which could be used in protecting coasts from probable sea level rising was experimentally studied using physical models by (Koraim et al. 2014). The hydrodynamic performance of vertical and sloped seawalls were investigated experimentally by (El Alfy et al 2015) using physical model studies under regular waves of wide range of heights, and periods.

A critical review of the existing literature reveals that the vertical seawalls has the disadvantage of increasing the water particle kinematics in front of the structure due to significant wave reflection, which results in increased wave loads on the seawall and increased toe scour. In order to overcome this difficulty, sloped seawalls had been introduced. Sloped seawalls are good energy dissipaters when compared to vertical seawalls, especially when the slope of the seawall becomes milder. Sloped seawalls cause a phase lag of reflected waves and induce waves to break on the slope by spilling and hence dissipate a part of the incident wave energy (Führböter 1994). But milder the slope of the seawall, the more expensive is. Therefore, sloped seawalls of different angles with the seabed with energy dissipaters in the form of rectangular or triangular serrated blocks, and horizontally slotted with triangular serrations or without any serrations are examined experimentally in this study.

\section{EXPERIMENTAL SETUP}

Several experiments are carried out in a wave flume $15.1 \mathrm{~m}$ long, $1.0 \mathrm{~m}$ wide and $1.0 \mathrm{~m}$ depth. A flap type wave generator is used to displace the water in the flume to get the desired wave characteristics. This wave generator is installed at one end of the flume. Two wave absorbers are used to prevent the reflec- 
tion of waves at the other end of the flume in order to increase the efficiency of experiments and to reduce the time required between runs while the water is calming down. The first absorber is placed in the front of the wave generator, while the other absorber is installed at the end of the flume with a slope of $1: 7$ as recommended by (Koraim \& Rageh 2013). The experiments are carried out with a constant water depth, $\mathrm{d}$, of $0.4 \mathrm{~m}$. The flap is controlled by an induction motor of $11 \mathrm{~kW}$. This motor is regulated by an inventor drive $(0-50 \mathrm{~Hz})$ rotating in a speed range of $0-155 \mathrm{rpm}$. Regular waves of heights, $\mathrm{H}_{\mathrm{i}}$, $(6.495$ to $11.1 \mathrm{~cm})$ of periods, $\mathrm{T},(0.669$ to $1.308 \mathrm{~s})$ have been generated with this facility.

\subsection{Model Details}

Five different types of the seawalls are examined covering different structural and wave conditions (i.e. plane seawall, plane wall with rectangular serrations, plane wall with triangular serrations, slotted seawall, and slotted seawall with triangular serrations) as shown in Figure 1.
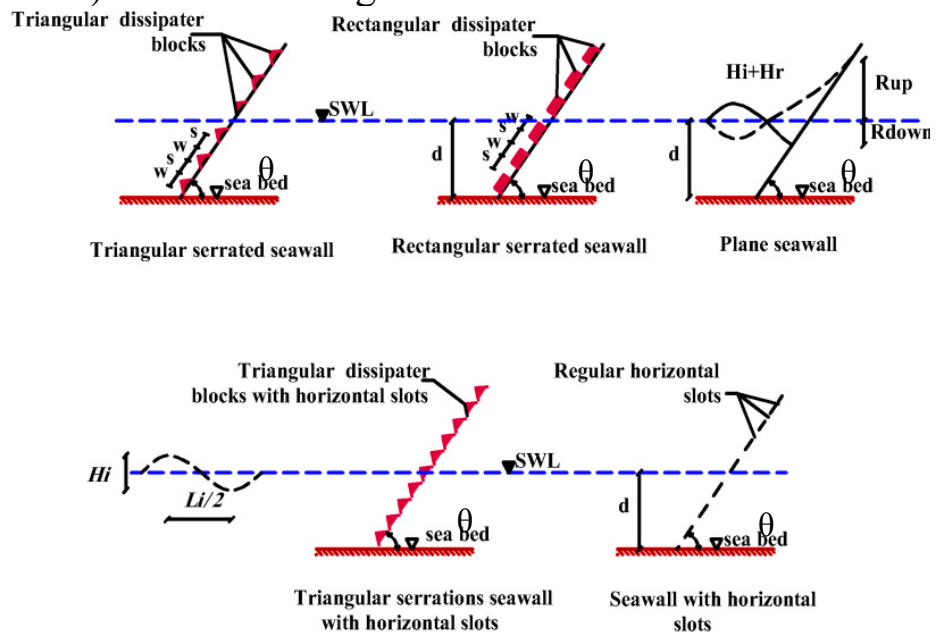

Figure 1. Definition sketches of seawalls physical models.

The tested models are placed at the middle of the wave flume. The models are fixed inside the wave flume rigidly for the required angle of inclination (i.e. $\theta=45,60,75$ and $90^{\circ}$ ) by using supports and wedges driven between the model and flume wall. The models consist of a plane plate, rectangular, and triangular dissipater blocks. Plate made of hardwood of thick $3 \mathrm{~mm}$ coated with water insulation material. Blocks are made of wood of sizes $99 \mathrm{~cm}$ length, $5 \mathrm{~cm}$ width (parallel to wall slope), $4 \mathrm{~cm}$ height (perpendicular on wall slope). They are fixed in a regular manner. The leakage of water between the model and the flume wall has been sealed by wooden planks.

\subsection{Parameters identification}

A dimensional analysis using Buckingham Pi theorem is performed in order to develop relationships of $\mathrm{K}_{\mathrm{r}}$ in terms of hydraulic and geometrical characteristics of the suggested models. The analysis presents the hydrodynamic performance in front of the seawall in terms of relationships between reflection coefficient, $K_{r}$, and the dimensionless parameters that represent the wave and structure characteristics as in the following equation:

$K_{r}=f\left(\frac{H_{i}}{L_{i}}, \xi, \frac{d}{L_{i}}, \frac{s}{w}, G, \cot \theta\right)=0.0$

The governing variables and their possible range of application are illustrated in Table 1, while the hydrodynamic performance of the tested seawalls have been checked in response to non-dimensional seawall and wave characteristic parameters as presented in Equation 1 and are listed in Table 2.

Table 1. Range of governing variables:

\begin{tabular}{|c|c|c|c|}
\hline Variable & Symbol & Unit & Range \\
\hline Water depth & d & $\mathrm{cm}$ & 40.0 \\
\hline Inventor frequency & - & $\mathrm{Hz}$ & $\begin{array}{l}\text { From } 2.5 \text { to } \\
4.9\end{array}$ \\
\hline Wave periods & $\mathrm{T}$ & $\sec$ & $\begin{array}{l}\text { From } 0.669 \\
\text { to } 1.308\end{array}$ \\
\hline Wave heights & $\mathrm{H}_{\mathrm{i}}$ & $\mathrm{cm}$ & $\begin{array}{l}\text { From } 6.495 \text { to } \\
11.1\end{array}$ \\
\hline $\begin{array}{l}\text { deep zone wave } \\
\text { height }\end{array}$ & $\mathrm{H}_{\mathrm{o}}$ & $\mathrm{cm}$ & $\begin{array}{l}\text { From } 5.93 \text { to } \\
11.093\end{array}$ \\
\hline $\begin{array}{l}\text { Incident wave } \\
\text { length }\end{array}$ & $\mathrm{L}_{\mathrm{i}}$ & $\mathrm{cm}$ & $\begin{array}{l}\text { From } 69.69 \text { to } \\
218.4\end{array}$ \\
\hline $\begin{array}{l}\text { Deep zone wave } \\
\text { length }\end{array}$ & $\mathrm{L}_{\mathrm{o}}$ & $\mathrm{cm}$ & $\begin{array}{l}\text { From } 69.82 \text { to } \\
266.89\end{array}$ \\
\hline $\begin{array}{l}\text { Angle of wave at- } \\
\text { tack }\end{array}$ & $\beta$ & - & $90^{\circ}$ \\
\hline Seabed angle & $\alpha$ & - & $0^{\circ}$ \\
\hline $\begin{array}{l}\text { Dissipater blocks } \\
\text { spacing }\end{array}$ & $\mathrm{s}$ & $\mathrm{cm}$ & $\begin{array}{l}5.0,10 \text {, and } \\
15\end{array}$ \\
\hline $\begin{array}{l}\text { Dissipater block } \\
\text { width in the direc- } \\
\text { tion } \\
\text { of seawall slope }\end{array}$ & W & $\mathrm{Cm}$ & 5.0 \\
\hline Slots ratio & G & - & $\begin{array}{l}0.13,0.23, \\
\text { and } 0.33 \text { per } 1 \\
\mathrm{~m}^{2}\end{array}$ \\
\hline Seawall slopes & $\theta$ & - & $\begin{array}{l}45,60,75, \\
\text { and } 90^{\circ}\end{array}$ \\
\hline
\end{tabular}

Table 2. Range of non-dimensional seawall and wave characteristics:

\begin{tabular}{ll}
\hline Parameter & Range \\
\hline Relative wave depth $\left(\mathrm{d} / \mathrm{L}_{\mathrm{i}}\right)$ & From 0.183 to 0.574 \\
Wave steepness $\left(\mathrm{H}_{\mathrm{i}} / \mathrm{L}_{\mathrm{i}}\right)$ & From 0.0297 to 0.1593 \\
$\begin{array}{l}\text { Surf similarity parameter } \\
(\xi)\end{array}$ & $\begin{array}{l}\text { From } 2.426 \text { to } 2.932 \text { (plunging } \\
\text { wave) }\end{array}$ \\
& $\begin{array}{l}\text { From } 3.394 \text { to } 23.924 \text { (surging } \\
\text { wave) }\end{array}$ \\
Relative dissipater blocks & $1.0,2.0$, and 3.0 \\
spacing $(\mathrm{s} / \mathrm{w})$ & $0.13,0.23$, and 0.33 \\
Slots ratio for $1.0 \mathrm{~m}^{2}(\mathrm{G})$ & $0,0.267,0.577$, and 1.0 \\
Cot $\theta$ & \\
\hline
\end{tabular}




\subsection{Instrumentation}

\subsubsection{Wave scales}

Vertical scales fixed with the Perspex part are used to measure the wave characteristics (i.e. P1, P2, and P3), see Figure 2. The accuracy of these scales is 1.0 $\mathrm{mm}$. The vertical scale is selected to be in front of the seawall model (seaward side) to measure the hydrodynamic parameter of waves (i.e. incident wave height, and wave reflected height).

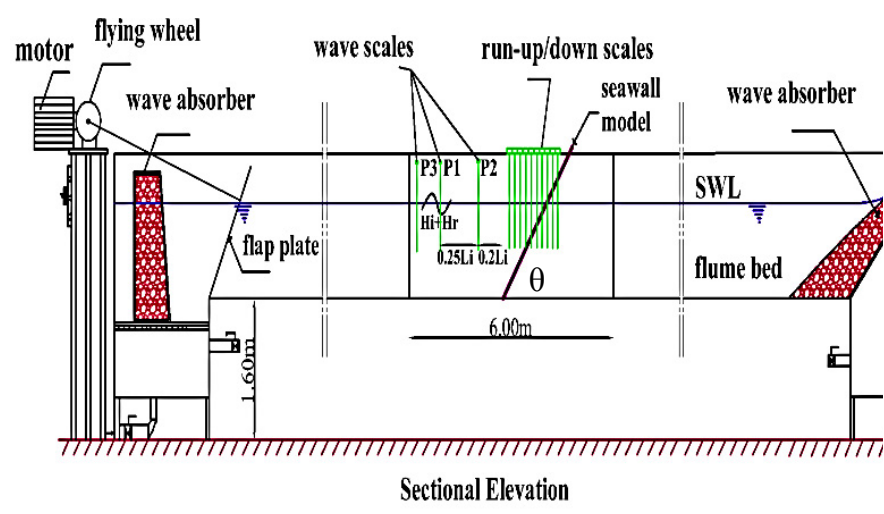

Figure 2. Sectional elevation for the used wave flume.

\subsubsection{Flume calibration}

Static calibration of the wave flume is carried out daily and at the inception of each set of experiments. The calibration variations are found to have a standard deviation of less than $0.5 \%$.

\subsubsection{Data acquisition}

A digital camera (e.g. auto focus 21 mega pixel, and optical zoom $5 \mathrm{x}$ ) is used for recording the wave characteristics. It is connected to a personal computer, in order to analyze the wave data. The camera is exactly adjusted perpendicular to the required vertical scale then fixed on a vertical stand on horizontal table to avoid vibrations during shots. The water level variation which resulted from the wave action is recorded by a camera for various frequencies, ranging from $2.5 \mathrm{~Hz}$ to $4.9 \mathrm{~Hz}$, at the selected measuring points. These data are converted to the wave elevations by simple computer program, and then the variation of water surface with time is plotted.

\subsubsection{Incident, and reflected wave heights}

The incident wave heights (Hi) are measured by using the wave probe P3. The values of the incident wave heights which calculated according to the method of (Dalrymple et al. 1991), are compared to those measured using wave probe $\mathrm{P} 3$. These values agreed quite closely (i.e. R-squared value equal to 0.977) as plotted in Figure 3.

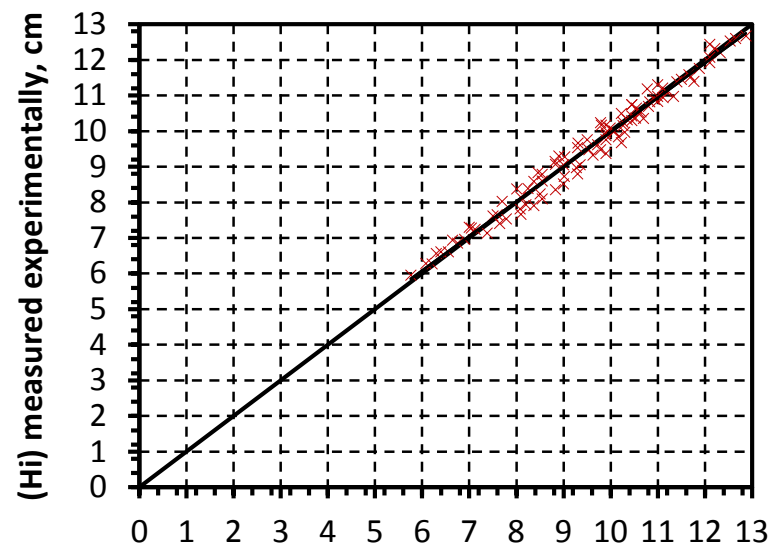

(Hi) by Dalrymple (1991), cm

Figure 3. Determination of incident wave height.

To separate the incident (Hi) and reflected (Hr) wave heights, two probes P2 and P1 (max. at location P1, the quasi-antinodes, and min. at location P2, the quasi-nodes) are set in front of the model at distances $0.2 \mathrm{~L}_{\mathrm{i}}$ and $0.45 \mathrm{~L}_{\mathrm{i}}$ respectively $\left(\mathrm{L}_{\mathrm{i}}\right.$ is the local incident wave length) measured from seawall toe according to (Dalrymple et al. 1991), as illustrated in Figure 2. The incident wavelength $L_{i}$ is variable according to the wave period $\mathrm{T}$, where it calculated by using the dispersion relationship according to the linear wave theory.

The water elevation $\eta(\mathrm{x})$ for any location $\mathrm{x}$, can be estimated by (Dalrymple et al. 1991) as follows:

$\eta(x)= \pm \sqrt{\begin{array}{l}\left(H_{i} / 2\right)^{2}+\left(H_{r} / 2\right)^{2}+ \\ \left(H_{i} H_{r} / 2\right) \cos (2 k x+\varepsilon)\end{array}}$

In which, $(\mathrm{k})$ is the wave number $\left(\mathrm{k}=2 \pi / \mathrm{L}_{\mathrm{i}}\right)$ and $(\varepsilon)$ is the phase lag induced by the reflection process. The $\eta(\mathrm{x})$ obviously varies periodically with $(\mathrm{x})$ and it becomes a maximum of the envelope at the phase positions,

$\left(2 \mathrm{kx}_{1}+\varepsilon\right)=2 \mathrm{n} \pi, \mathrm{n}=0,1,2, \ldots$

$\eta(\mathrm{x})_{\max .}=\left(\mathrm{H}_{\mathrm{i}}+\mathrm{H}_{\mathrm{r}}\right) / 2$ (the quasi-antinodes)

Whereas at the phase positions,

$\left(2 \mathrm{kx}_{2}+\varepsilon\right)=(2 \mathrm{n}+1) \pi, \mathrm{n}=0,1,2, \ldots$

It becomes a minimum of the envelope:

$\eta(\mathrm{x})_{\min .}=\left(\mathrm{H}_{\mathrm{i}}-\mathrm{H}_{\mathrm{r}}\right) / 2$ (the quasi-nodes)

It is easy to obtain the actual distance between vertical scales $\mathrm{P}_{1}$ and $\mathrm{P}_{2}$ by subtracting Equation 5 from Equation 3, so it will be equal to $\mathrm{L}_{\mathrm{i}} / 4$. 

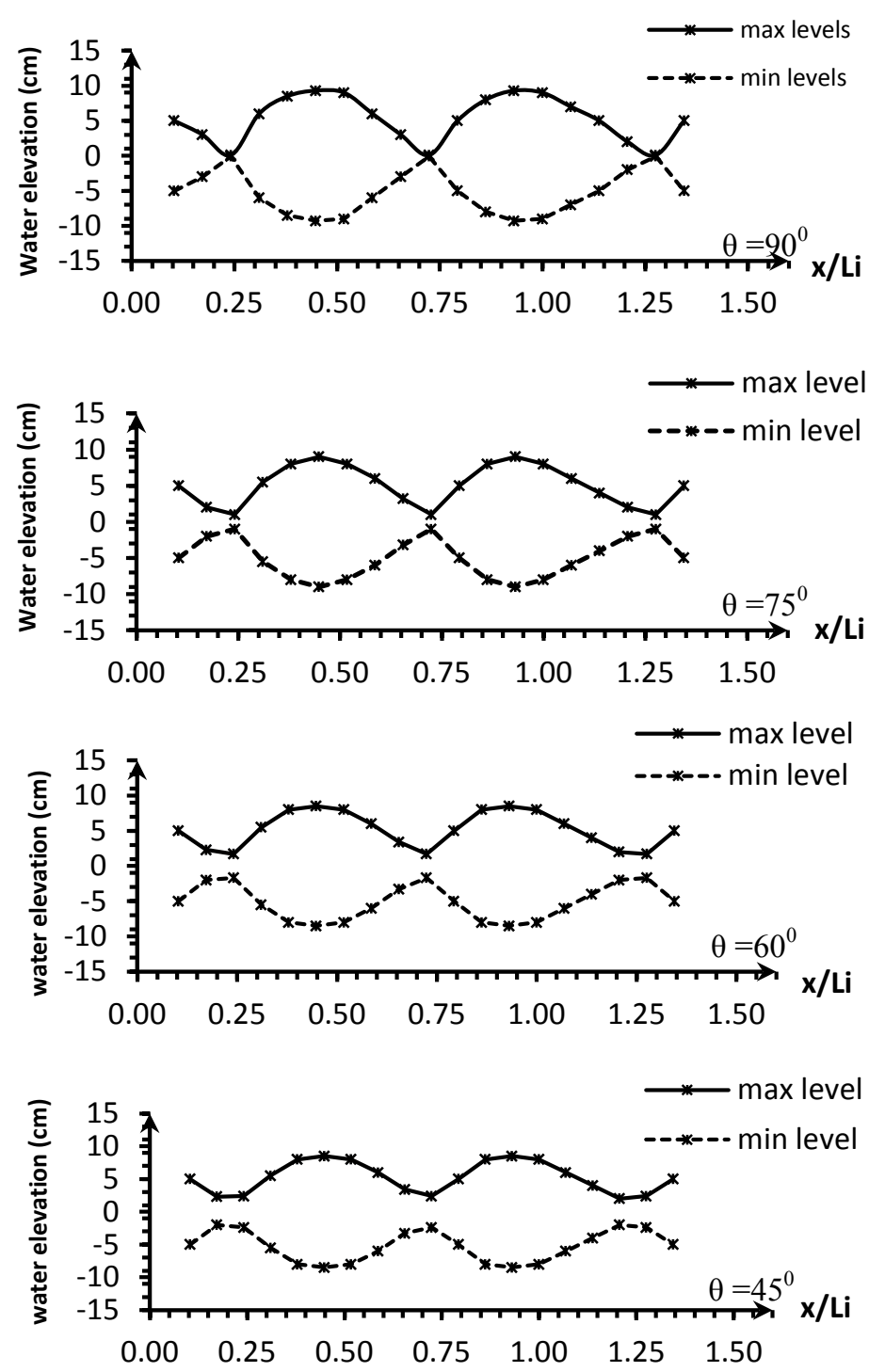

Figure 4. Partial standing wave envelope for the case of plane seawall at different slope angles at $\left(\mathrm{H}_{\mathrm{i}}=9.4 \mathrm{~cm}, \mathrm{~L}_{\mathrm{i}}=144.7 \mathrm{~cm}\right.$, and $\mathrm{T}=0.994 \mathrm{sec})$.

To verify this, a typical envelope of the partial standing wave induced by a plane wall (for slope angles $(\theta)=90^{\circ}, 75^{\circ}, 60^{\circ}$, and $45^{\circ}, \mathrm{L}_{\mathrm{i}}=144.7 \mathrm{~cm}$, $\left.\mathrm{H}_{\mathrm{i}}=9.4 \mathrm{~cm}, \mathrm{~T}=0.994 \mathrm{sec}\right)$ are measured and plotted in Figure 4. In this figure, maximum and minimum wave elevations measured at different spatial positions along the wave flume at $0.1 \mathrm{~m}$ intervals from $\mathrm{x}=0.15$ to $1.95 \mathrm{~m}$ are given. In a partial standing wave field, nodes and antinodes alternate spatially at $\mathrm{x}$ locations at increments of $\mathrm{L}_{\mathrm{i}} / 4$.

The calculated incident $\left(\mathrm{H}_{\mathrm{i}}\right)$ and reflected $\left(\mathrm{H}_{\mathrm{r}}\right)$ wave heights estimated from Equations (4) and (6) as:

$$
\begin{aligned}
& H_{i}=\eta_{\text {max }}+\eta_{\text {min }}=\frac{H_{\text {max }}+H_{\text {min }}}{2} \\
& H_{r}=\eta_{\text {max }}-\eta_{\text {min }}=\frac{H_{\text {max }}-H_{\text {min }}}{2}
\end{aligned}
$$

Where:

$\mathrm{H}_{\max }=\max$ wave height (at antinodes) $=$ max crest level - min through level; and

$\mathrm{H}_{\min }=\min$ wave height (at nodes) = min crest levelmax through level.

The reflection coefficient, $\mathrm{K}_{\mathrm{r}}$, is the ratio between reflected and incident wave heights, therefore:

$$
\begin{aligned}
& \mathrm{K}_{\mathrm{r}}=\mathrm{H}_{\mathrm{r}} / \mathrm{H}_{\mathrm{i}} \\
& K_{r}=\frac{H_{\text {max }}-H_{\text {min }}}{H_{\text {max }}+H_{\text {min }}}
\end{aligned}
$$

A typical time series for the variation of water levels for the standing wave obtained from plane wall at different wall slopes $\left(\mathrm{H}_{\mathrm{i}}=9.4 \mathrm{~cm}, \mathrm{~L}_{\mathrm{i}}=144.7 \mathrm{~cm}\right.$ , and $\mathrm{T}=0.994 \mathrm{sec}$ ) is presented in Figure 5.

As shown from Figure 5, the standing wave begins to start after 16 seconds in the case of slope angle $90^{\circ}$, while it begins to start after $19 \mathrm{sec}$, and 23 sec for slope angles $75^{\circ}$, and $60^{\circ}$ respectively. It is noticed that whenever the slope become milder, the occurrence of the standing waves become more late. This lag of time occur due to the excessive dissipation of energy for the waves on the seawalls slopes due to wave breaking.

\section{ANALYSIS AND RESULTS}

\subsection{Results of wave investigations}

\subsubsection{General}

Investigating the effect of $\xi$, wave periods interms of $\mathrm{d} / \mathrm{Li}$, and wave heights interms of $\mathrm{Hi} / \mathrm{Li}$ on $\mathrm{k}_{\mathrm{r}}$ is not only essential to understand the hydrodynamic characteristics of the existing seawall for coastal regions, but also, it helps realizing the performance of the seawall under normal and extreme wave actions. Moreover, investigating the effect of $\mathrm{s} / \mathrm{w}, \mathrm{G}$, and $\cot \theta$ on $\mathrm{k}_{\mathrm{r}}$ is required to select the appropriate structures configuration. 

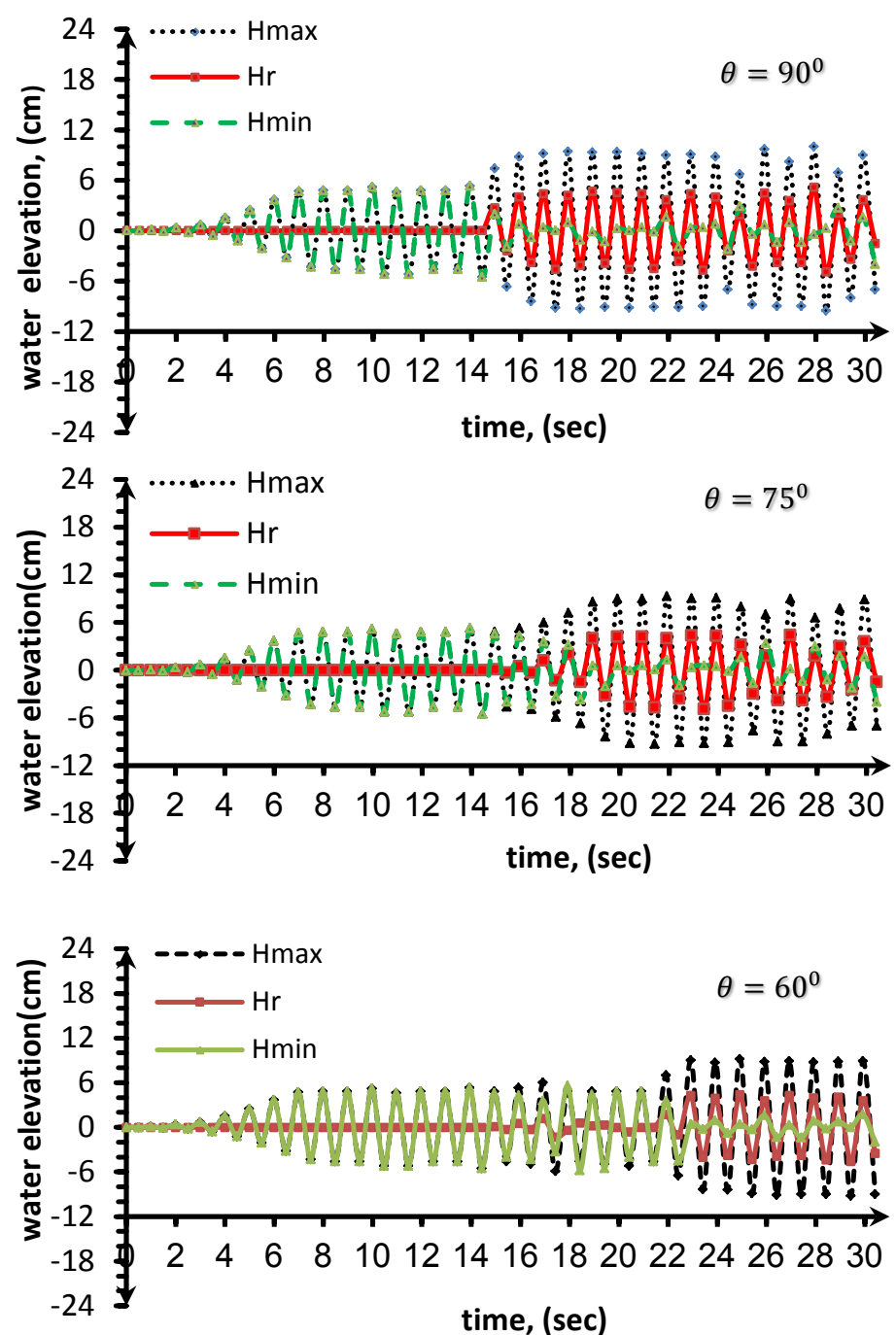

Figure 5.Typical time series of the variation of water levels for the standing wave obtained from plane wall at different slopes

$\left(\mathrm{H}_{\mathrm{i}}=9.4 \mathrm{~cm}, \mathrm{~L}_{\mathrm{i}}=144.7 \mathrm{~cm}\right.$, and $\left.\mathrm{T}=0.994 \mathrm{sec}\right)$.

\subsubsection{Effect of surf similarity parameter $\xi$ on $k_{r}$}

Surf similarity parameter (Iribarren number) $\xi$ is one of the important influencing parameters for sloped faced seawalls (Twu \& Liu 1999).

(Battjes 1974) defined $\xi$ as:

$\xi=\frac{\tan \theta}{\sqrt{H_{i} / L_{o}}}$

Figure 6 is provided for illustrating the effect of surf similarity parameter $\xi$ from the range of 3.394 to 23.924 for the five tested seawalls. It can be seen in general that $\mathrm{K}_{\mathrm{r}}$ value increases with increased $\xi$.
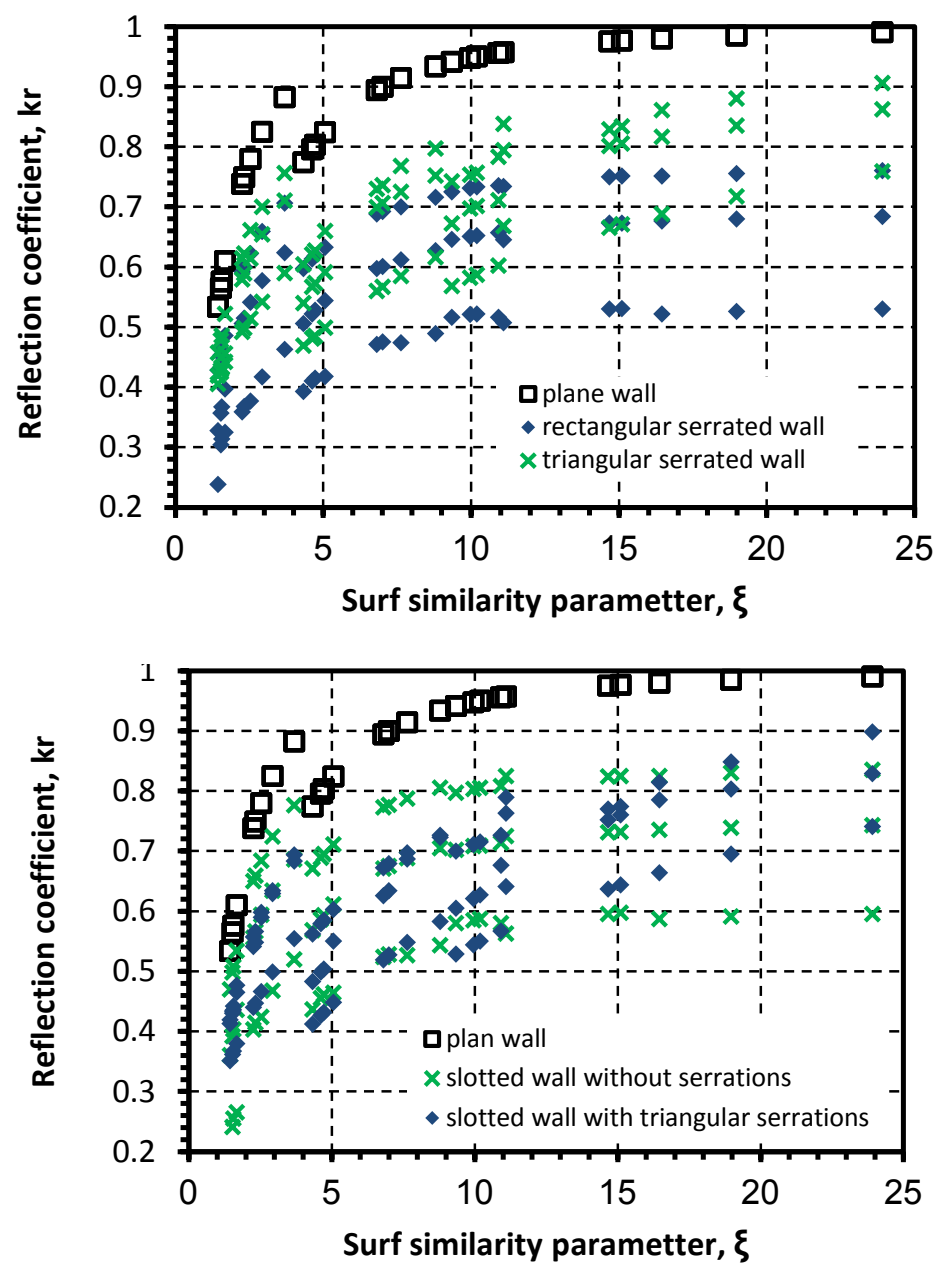

Figure 6. Effect of surf similarity parameter $(\xi)$ on reflection coefficient $\left(\mathrm{k}_{\mathrm{r}}\right)$.

\subsubsection{Effect of wave height on $k_{r}$}

Figure 7 depicts the influence of wave height on wave reflection coefficient $\left(k_{r}\right)$ in terms of wave steepness parameter $\left(\mathrm{H}_{\mathrm{i}} / \mathrm{L}_{\mathrm{i}}\right)$ for the plane, rectangular serrated seawall with $(\mathrm{s} / \mathrm{w}=2.0)$, triangular serrated seawall with $(\mathrm{s} / \mathrm{w}=2.0)$, plane wall with regular horizontal slots at slot ratio $(\mathrm{G}=0.33)$, and plane wall with regular horizontal slots combined with triangular serrations at slot ratio $(\mathrm{G}=0.33)$ for slope angle $60^{\circ}$. The values of $K_{r}$ in the sequence of the above five tested models decreases from $(0.95$ to $0.77),(0.641$ to 0.412$),(0.668$ to 0.469$),(0.563$ to $0.437)$, and $(0.507$ to 0.393$)$, while the wave steepness increases from (0.0297 to 0.437$)$ due to the excessive energy dissipation of the steeper waves, see Figure 8. This dissipation part of the wave energy can be estimated in terms of non-dimensional parameter called relative energy dissipation, $\left(\mathrm{R}_{\mathrm{L}}\right)$. The value of $\mathrm{R}_{\mathrm{L}}$ could be evaluated as a function of reflection coefficient as given by (Reddy \& Neelamani 1992):

$R_{L}=1-k_{r}^{2}$

Figure 7 also shows that the rectangular serrated seawall with $\mathrm{s} / \mathrm{w}=2.0$ gives results for wave reflection coefficient reduction better than the 
slotted seawall with $\mathrm{G}=0.33$ for wave steepness bigger than 0.065 . The slotted wall with triangular serrations give the least reduction for $\mathrm{K}_{\mathrm{r}}$ compared with the other tested models for $\theta=60^{\circ}$.

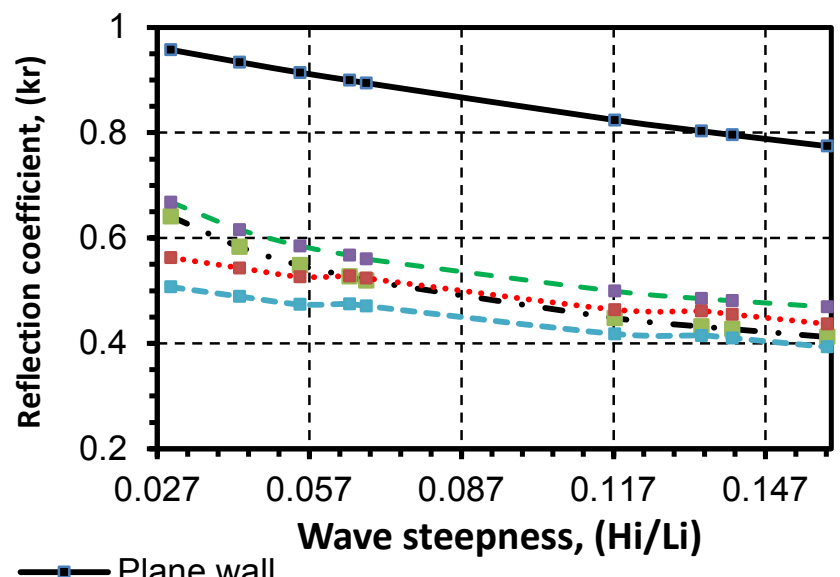

Plane wall

- - Rectangular serration ( $\mathrm{s} / \mathrm{w}=2.0)$

- - Triangular serration $(\mathrm{s} / \mathrm{w}=2.0)$

...... Horizontal slots $(\mathrm{G}=0.33)$

Slots with triangular serration $(G=0.33)$

Figure 7. Effect of wave height $\left(\mathrm{H}_{\mathrm{i}} / \mathrm{L}_{\mathrm{i}}\right)$ on $\mathrm{K}_{\mathrm{r}}$ for the five tested models at wall slope $(\theta)=60^{\circ}$.

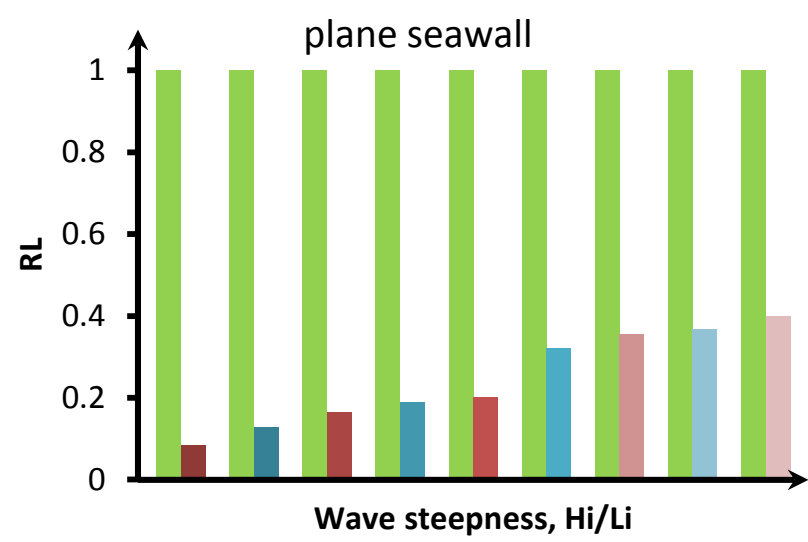

Figure 8. Effect of wave steepness $\left(\mathrm{H}_{\mathrm{i}} / \mathrm{L}_{\mathrm{i}}\right)$ on wave energy dissipation for plan wall wall at slope angle $\left(\theta=60^{\circ}\right)$.

\subsubsection{Effect of wall slope on $k_{r}$}

The effect of wall slope on wave reflection coefficient is studied at three different wave periods [i.e. $\mathrm{d} / \mathrm{Li}$ ranges from $(0.183$ to 0.263$),(0.276$ to 0.45$)$, and $(0.495$ to 0.574$)$ for long, short, and shorter waves respectively] for plane seawall, rectangular serrated seawall with relative spacing between dissipater blocks $(\mathrm{s} / \mathrm{w}=2.0)$, triangular serrated seawall with relative spacing between dissipater blocks $(\mathrm{s} / \mathrm{w}$ $=2.0$ ), plane wall with regular horizontal slots at slot ratio $(\mathrm{G}=0.33)$, and plane wall with regular horizontal slots combined with triangular serrations at slot ratio $(\mathrm{G}=0.33)$.
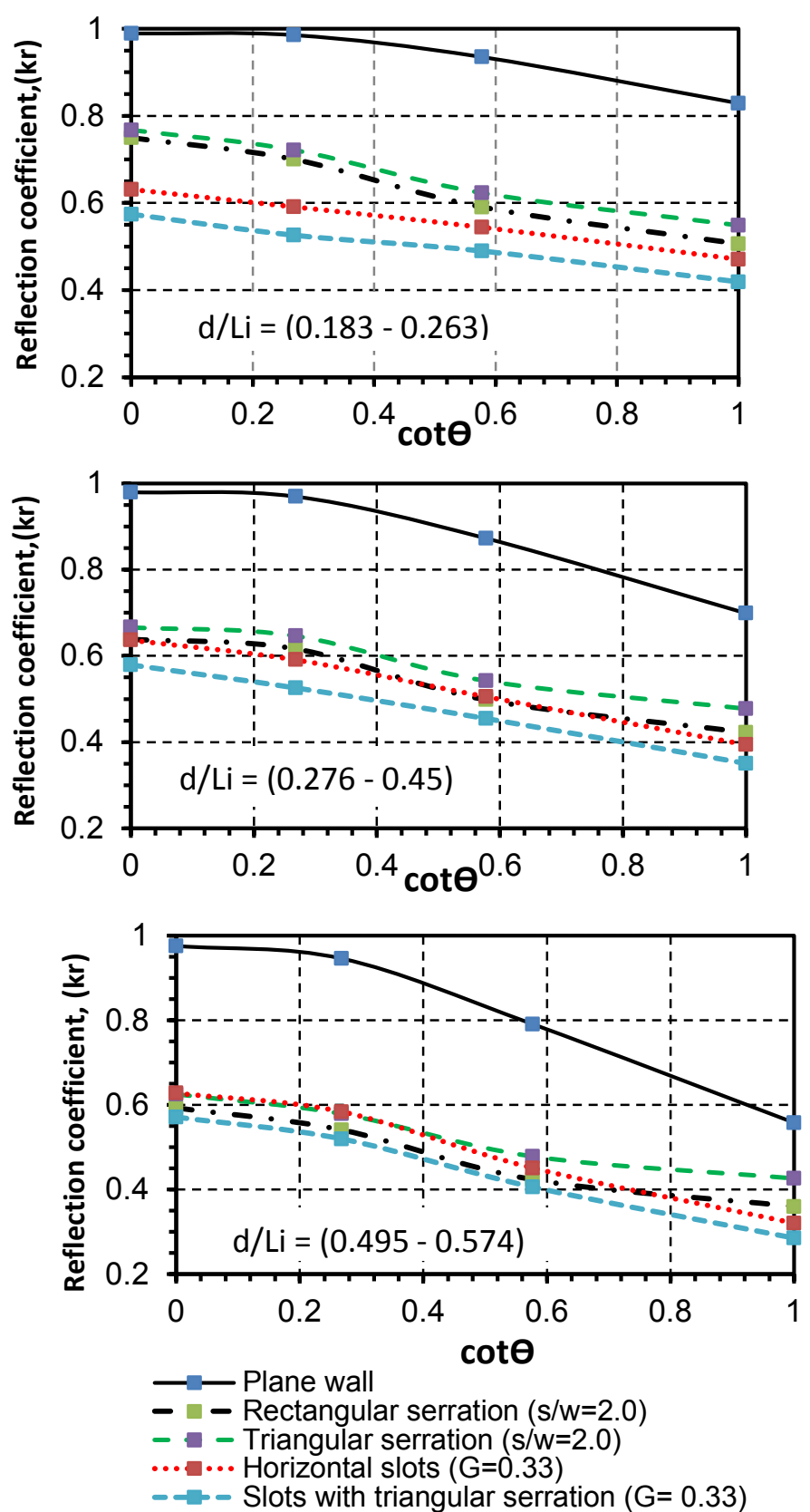

Figure 9. Effect of slope angle $(\theta)$ on $\left(\mathrm{k}_{\mathrm{r}}\right)$ for the five tested models at different wave periods $\left(\mathrm{d} / \mathrm{L}_{\mathrm{i}}\right)$

Generally, for $\mathrm{d} / \mathrm{Li}$ varies from 0.183 to 0.574 , it is found that the $\mathrm{Kr}$ value decreases with increasing $(\cot \theta)$ value for the five tested models due to wave breaking on the sloped surface by surging or plunging, see Figure 9.

On other hand through Figure 9, it is observed that the effect of the slope of the seawall is more significant on $\mathrm{K}_{\mathrm{r}}$ reduction for the shorter waves (i.e. $\mathrm{d} / \mathrm{L}_{\mathrm{i}}$ from 0.495 to 0.574 ) compared with the longer waves (i.e. $\mathrm{d} / \mathrm{L}_{\mathrm{i}}$ from 0.183 to 0.263 ) spacially for the plane seawall.

\subsubsection{Effect of blocks spacing (s) on $k_{r}$}

Spacing between blocks is considered a significant parameter for determination of the optimum design critrea of seawall configuration. Figure 10 shows 
the influince of relative spacing between the energy disspater blocks $(\mathrm{s} / \mathrm{w})$ on the values of wave reflection coefficient for both rectangular and triangular seawalls at the different selected slope angles.
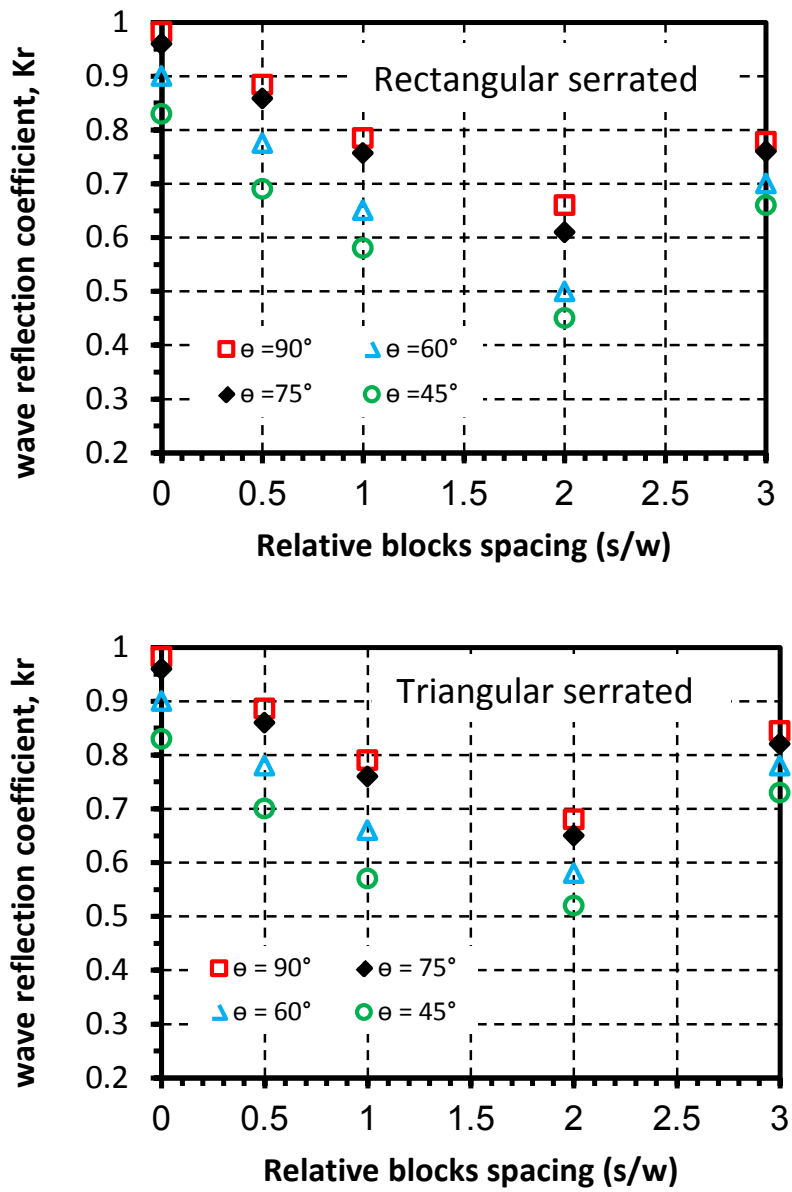

Figure 10. Effect of relative blocks spacing $(\mathrm{s} / \mathrm{w})$ on $\left(\mathrm{k}_{\mathrm{r}}\right)$ for rectangular and triangular serrated walls at different slopes $(\theta)$

It is observed for both the rectangular and triangular serrated walls that the optimum values of wave reflection coefficient occur when spacing between blocks (s) equal to double the width of the dissipater block (w) at all selected wall slopes.

\subsubsection{Predetcive equations}

Based on the above dimensionless parameters in Equation 1, a non-linear regression analysis is carried out on about $70 \%$ of the observed data using SPSS (Levesque 2006) to obtain predictive equations for estimating the values of $\mathrm{K}_{\mathrm{r}}$ as follow:

$$
\begin{aligned}
& K_{r}=a_{1}\left(\frac{d}{L_{i}}\right)^{b_{1}}\left(\frac{H_{i}}{L_{i}}\right)^{c_{1}}(\xi)^{d_{1}}(\cot \theta)^{e_{1}} \\
& \left(\frac{s}{w}\right)^{f_{1}}(G)^{g_{1}}
\end{aligned}
$$

The values of parameters, $a_{1}, b_{1}, c_{1}, d_{1}, e_{1}, f_{1}$ and $\mathrm{g}_{1}$ for plane, rectangular serrated, triangular serrated seawall, slotted seawall, and slotted seawall with triangular serrations in case of vertical and sloped wall faces are listed in Table 3.
Table 3. Estimated parameters of equation 13 for predicting

\begin{tabular}{|c|c|c|c|c|c|c|c|}
\hline \multicolumn{8}{|c|}{ Vertical seawall $(\cot \theta=0.0)$} \\
\hline Wall type & $\mathrm{a}_{1}$ & $\mathrm{~b}_{1}$ & $\mathrm{c}_{1}$ & $\mathrm{~d}_{1}$ & $\mathrm{e}_{1}$ & $\mathrm{f}_{1}$ & $\mathrm{~g}_{1}$ \\
\hline $\begin{array}{l}\text { Plane } \\
\mathrm{R}^{2}=0.91\end{array}$ & 0.92 & 0.05 & -0.04 & 0.0 & 0.0 & 0.0 & 0.0 \\
\hline $\begin{array}{l}\text { Rectangular } \\
\text { Serrated } \\
\mathrm{R}^{2}=0.55\end{array}$ & 0.4 & 0.33 & -.039 & 0.0 & 0.0 & $\begin{array}{l}- \\
0.03\end{array}$ & 0.0 \\
\hline $\begin{array}{l}\text { Triangular } \\
\text { serrated } \\
\mathrm{R}^{2}=0.5\end{array}$ & 0.48 & 0.17 & -0.25 & 0.0 & 0.0 & 0.03 & 0.0 \\
\hline $\begin{array}{l}\text { Slotted, } \\
\mathrm{R}^{2}=0.99\end{array}$ & 0.4 & 0.02 & -0.02 & 0.0 & 0.0 & 0.0 & $\overline{-}$ \\
\hline $\begin{array}{l}\text { Slotted }+ \\
\text { triangular } \\
\text { serrations, } \\
\mathrm{R}^{2}=0.99\end{array}$ & 0.4 & -0.05 & 0.01 & 0.0 & 0.0 & 0.0 & $\overline{-}-3$ \\
\hline \multicolumn{8}{|c|}{ Sloped seawall $(\cot \theta$ from 0.267 to 1.0$)$} \\
\hline Wall type & $a_{1}$ & $\mathrm{~b}_{1}$ & $\mathrm{c}_{1}$ & $\mathrm{~d}_{1}$ & $\mathrm{e}_{1}$ & $f_{1}$ & $\mathrm{~g}_{1}$ \\
\hline $\begin{array}{l}\text { Plane } \\
\mathrm{R}^{2}=0.82\end{array}$ & 0.51 & -0.1 & -0.48 & -0.76 & -1.0 & 0.0 & 0.0 \\
\hline $\begin{array}{l}\text { Rectangular } \\
\text { Serrated } \\
\mathrm{R}^{2}=0.78\end{array}$ & 0.25 & 0.06 & -0.82 & -1.0 & -1.3 & $\begin{array}{l}- \\
0.06\end{array}$ & 0.0 \\
\hline $\begin{array}{l}\text { Triangular } \\
\text { serrated } \\
\mathrm{R}^{2}=0.74\end{array}$ & 0.31 & -0.07 & -0.61 & -0.8 & -1.1 & 0.04 & 0.0 \\
\hline $\begin{array}{l}\text { Slotted, } \\
\mathrm{R}^{2}=0.9\end{array}$ & 0.29 & -0.34 & 0.9 & 1.4 & 1.2 & 0.0 & $\begin{array}{l}- \\
0.4\end{array}$ \\
\hline $\begin{array}{l}\text { Slotted }+ \\
\text { triangular } \\
\text { serrations, } \\
\mathrm{R}^{2}=0.9\end{array}$ & 0.25 & -0.34 & 0.94 & 1.48 & 1.3 & 0.0 & $\overline{-}$ \\
\hline
\end{tabular}
wave reflection for different seawall types.

\subsubsection{Data verification}

The remaining $30 \%$ of the observed data are used to verify the predicted values of $\mathrm{K}_{\mathrm{r}}$ which obtained from Equation 12. The data points are reasonably distributed on either side of a $45^{\circ}$ line which is used for observing the correlation between the predicted and observed $K_{r}$. Figure 11 is plotted to depicts the correlation between the measured and predicted values of $\mathrm{K}_{\mathrm{r}}$ for the five tested walls for the sloped case. It is noticed that the agreement between observed and predicted values is slightly converged.

\subsubsection{Data validation}

The empirical equations are validated by comparison with previous predictions and experiments for the limiting cases of the seawall.

Figure 12 demonstrates a comparison between the results of present work (i.e. plane impermeable seawall) and the results of other authors and formulas for predicting the wave reflection coefficient for sloped plane impermeable seawalls for a wide range of slope angles (i.e. $0.267 \leq \cot \theta \leq$ 1.0), wave periods (i.e. $\mathrm{d} / \mathrm{L}_{\mathrm{i}}=0.183$ to 0.574 ), wave steepness (i.e. $\mathrm{H}_{\mathrm{i}} / \mathrm{L}_{\mathrm{i}}=0.0297$ to 0.1593 ), and Iribarin number $(\xi)$ varies from 2.5 to 24 . 
The different formulas which used for predicting the values of $\mathrm{K}_{\mathrm{r}}$ are described as follow:

For present study:

$k r=0.513\left(\mathrm{~d} / L_{i}\right)^{-0.091}\left(H_{i} / L_{i}\right)^{-0.487}(\xi)^{-0.76}$
$(\cot \theta)^{-0.983}$

After (Neelamani \& Sandhya 2003):

$k r=0.08 \ln (\xi)+0.65$

After (Neelamani \& Sandhya 2005):

$k r=0.9-(0.52 / \xi)$

After (Allsop \& Hettiarachchi 1988):

$K_{r}=a \xi^{2} / b+\xi^{2}$

After (Ahrens et al. 1993):

$K_{r N B}=1-e^{\left(\chi\left(a^{-}+b^{-} \beta\right)\right)}$

where:

$$
\chi=d^{*} \cot \theta / L i
$$

$\mathrm{a}^{-}$and $\mathrm{b}^{-}$are empirical constants; and

$\beta=\left(H_{i} / L_{i}\right)\left(\tanh ^{3}\left(2 \pi d / L_{i}\right)\right)$

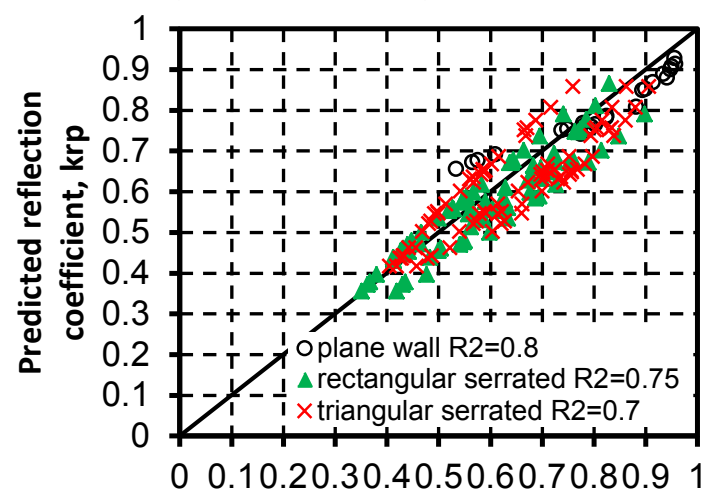

Measured reflection coefficient, krm

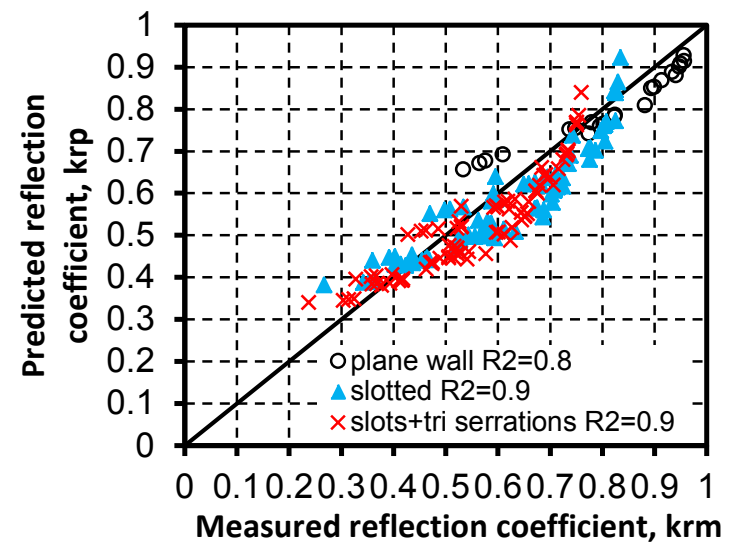

Figure 11. Comparison between the measured and predicted wave reflection coefficient for the five selected sloped walls by using nonlinear regression.

The figure shows that for all formulas, reflection coefficient $\left(\mathrm{K}_{\mathrm{r}}\right)$ increases as Iribarin number $(\xi)$ increase. The results of Equation 13 give a good consistency with the results obtained by(Ahrens et al. 1993), and (Neelamani \& Sandhya 2005), while the agreement with the results obtained by (Allsop \& Hettiarachchi 1988) become good when $\xi \succ 14$.

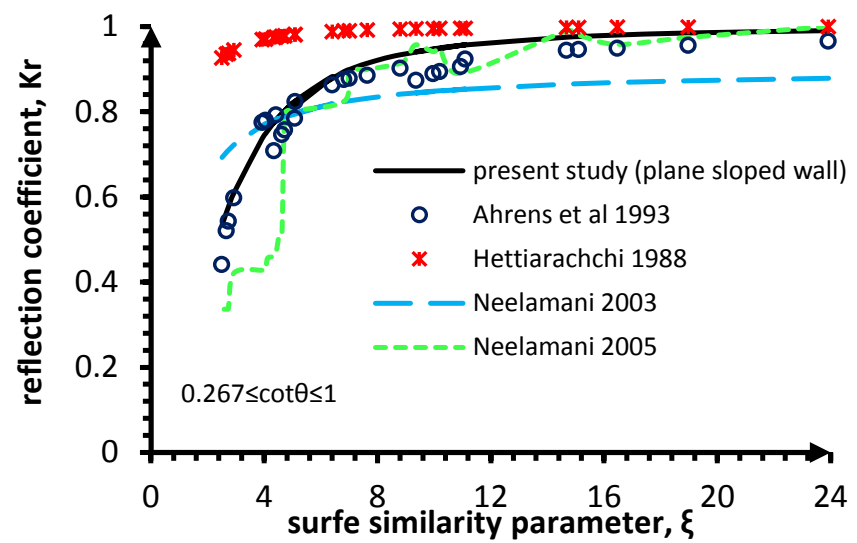

Figure 12. Comparison between the present study (plane smooth wall) with previous works for wave reflection coefficient versus surf similarity parameter.

Figure 13 presents a comparison between the results of present work (i.e. vertical slotted seawall, $\mathrm{G}=0.33$; and vertical slotted triangular serrated seawall, $\mathrm{G}=0.33$ ) and the results of other authors and formulas for predicting the wave reflection coefficient for vertical porous seawalls.

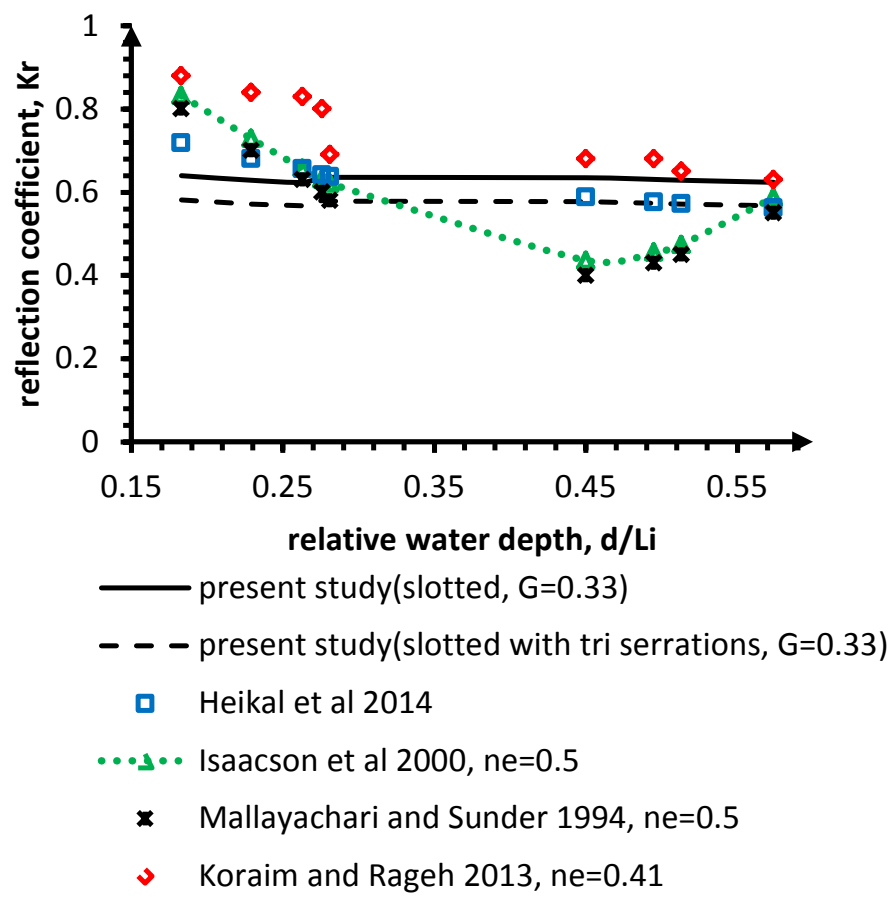

Figure 13. Comparison between the present study (vertical slotted wall and slotted triangular serrated wall) with previous works for wave reflection coefficient versus relative water depth.

The different formulas which used for predicting the values of $\mathrm{K}_{\mathrm{r}}$ at wave periods (i.e. $\mathrm{d} / \mathrm{L}_{\mathrm{i}}=0.183$ to 0.574 ), wave steepness (i.e. $\mathrm{H}_{\mathrm{i}} / \mathrm{L}_{\mathrm{i}}=0.0297$ to $0.1593)$ are described as follow:

For present study: 
Slotted seawall:

$k r=0.431\left(d / L_{i}\right)^{0.017}\left(H_{i} / L_{i}\right)^{-0.019}(G)^{-0.317}$

Slotted seawall with triangular serrations:

$k r=0.409\left(d / L_{i}\right)^{-0.048}\left(H_{i} / L_{i}\right)^{0.006}(G)^{-0.297}$

After (Koraim \& Rageh 2013) [for wall porosity, $\left.\mathrm{n}_{\mathrm{e}}=0.41\right]$ :

$k r=-0.59 d / L_{i}+0.95$

After (Heikal et al. 2014) [for wall porosity, $\left.\mathrm{n}_{\mathrm{e}}=0.33\right]$ :

$k_{r}=0.24\left(d / L_{i}\right)^{-0.01}\left(H_{i} / L_{i}\right)^{-0.14}(b / d)^{-0.20}\left(n_{e}\right)^{-0.53}$

Where, (b) = the width of porous wall in the direction of wave propagation.

The values of $\mathrm{K}_{\mathrm{r}}$ which obtained by (Mallayachari \& Sundar 1994) and (Isaacson et al. 2000) were figured based on numerical studies at wall porosity, $\mathrm{n}_{\mathrm{e}}=0.5$. The figure shows that the general trend of $\mathrm{K}_{\mathrm{r}}$ decreases as $d / L_{i}$ increase for all studies.

The variation between results in figures 12 and 13 is due to the variable experimental set up, design criteria of the experiments, and limitation of each study.

\section{CONCLUSION}

A hdrodynamic performance evaluation is done for seawalls in terms of wave reflection coefficient and it is found that both rectangular and triangular serrations reduces the wave reflection coefficient by about $42 \%$ and $36 \%$, respectively, while both plane slotted seawalls without and with triangular serrations reduce wave reflection by about $43 \%$ and $49 \%$,respectively. These results show that the triangular slotted seawall have the best hydrodynamic performance compared with the other four tested models.

Adding a rectangular blocks on a plane wall increase energy dissipation by $31 \%$ to $52 \%$, while adding triangular serrations increase energy dissipation by $26 \%$ to $49 \%$. So, the rectangular blocks are better energy dissipaters compared with triangular blocks.

Adding a triangular serrations to the plane slotted wall increase the energy dissipation by $3 \%$ to $7 \%$.

As well it is found that the relative spacing of dissipater blocks, slots ratio, slope angle, wave steepness, surf similarity parameter, and the relative water depth are better influencing parameters in predicting the wave reflection coefficient.

Both the rectangular and triangular serrated walls have the optimum values of wave reflection coefficient when spacing between blocks (s) equal to double the width of the dissipater block (w) at all selected wall slopes.

Based on both the dimensional analysis and measurements, predictive formulas are proposed to predict the reflection coefficient due to regular waves for five tested models by using SPSS software. These formulas are compared with experimental and theoretical results obtained by different authors and giving a reasonable agreement.

It is recommended through this research to make use the results on different coastal aspects, such as the design of energy dissipating type vertical quay wall in ports and harbors, sloped seawalls for shore protection from erosion, stability of revetments on the navigation canals sides, waves absorber which used in laboratory flumes or sloped caisson as breakwaters.

\section{ACKNOWLEDGEMENT}

The author would like to thank the Egyptian Ministry of Higher Education (MoHE) for providing him the financial support for his PhD scholarship. Also, he would like to express his sincere thanks to the technical staff Hydraulics Laboratory, Irrigation and Hydraulics Dept, Faculty of Engineering, ElMansoura University, Egypt for their valuable assistance during the experimental part of this research.

\section{SYMBOLS AND RIVIATIONS}

Symbols:

a, and :Constants used in formulas for determination

b of wave reflection coefficient;

d : Still water depth;

G : Slots ratio per $1.0 \mathrm{~m}^{2}$;

$\mathrm{H}_{\mathrm{i}} \quad$ : Incident wave height;

$\mathrm{H}_{\mathrm{o}} \quad$ : Deep zone wave height;

$\mathrm{H}_{\mathrm{r}} \quad$ : Reflected wave height;

$\mathrm{K}_{\mathrm{r}} \quad$ : Reflection coefficient;

$\mathrm{L}_{\mathrm{i}} \quad$ : Incident wave length;

$\mathrm{L}_{\mathrm{o}} \quad$ : Deep zone wave length;

$\mathrm{n}_{\mathrm{e}} \quad$ : Porosity of porous seawall;

$\mathrm{P}_{1}, \quad$ : Wave recorders;

$\mathrm{P}_{2}, \mathrm{P}_{3}$

$\mathrm{R}_{\mathrm{L}} \quad$ : Relative wave energy dissipation;

$\mathrm{S} \quad$ :Net spacing between dissipater blocks;

$\mathrm{T} \quad$ : Wave period;

w :Width of dissipater blocks in the direction of wall slope; and 
$\theta \quad$ :Slope angle between seawall and seabed;

$\alpha \quad$ :Sea bed angle;

$\eta(x) \quad$ :Water elevation above still water level at location (x) from wall toe;

$\eta_{\max } \quad$ :Maximum water elevation above still water level;

$\eta_{\min }$ :Minimum water elevation above still water level.

$\beta \quad$ :Angle of wave attack;

$\xi \quad$ :Surf similarity parameter (Iribarren number); and

$\chi \quad$ :Factor used in determination of wave reflection coefficient for non-breaking waves.

\section{Abbreviations}

SPSS: Statistical Package for Social Science.

SWL: Still Water Level.

\section{REFERENCES}

Ahrens, J.P. et al., 1993. Wave runup on and wave reflection from coastal structures. In Ocean Wave Measurement and Analysis. pp. 489-502.

El Alfy, Kassem., Rageh, Osami. and Nassar, K., 2015. Wave Hydrodynamics Characteristics on Vertical and Slopped Seawalls. MANSOURA ENGINEERING JOURNAL, ISSN-1110 0141, 40(1), pp.1-18.

Allsop, N.W.H. \& Hettiarachchi, S.S.L., 1988. Reflections from coastal structures. Coastal Engineering Proceedings, $1(21)$.

Battjes, J.A., 1974. Surf similarity. Coastal Engineering Proceedings, 1(14).

Chen, H.-B., Tsai, C.-P. \& Chiu, J.-R., 2006. Wave reflection from vertical breakwater with porous structure. Ocean engineering, 33(13), pp.1705-1717.

Dalrymple, R.A., Losada, M.A. \& Martin, P.A., 1991. Reflection and transmission from porous structures under oblique wave attack. Journal of Fluid Mechanics, 224, pp.625-644.

Führböter, A., 1994. Wave loads on sea dikes and sea-walls. Abbott, MB; Price, WA: Coastal, Estuarial and Harbour Engineers' Reference Book, London/Glasgow, England,, pp.351-367.

Isaacson, M. et al., 2000. Wave interactions with perforated breakwater. Journal of waterway, port, coastal, and ocean engineering, 126(5), pp.229-235.

Koraim, A.S., Heikal, E.M. \& Abo Zaid, A.A., 2014. Hydrodynamic characteristics of porous seawall protected by submerged breakwater. Applied Ocean Research, 46, pp.114.

Koraim, A.S. \& Rageh, O.S., 2013. Hydrodynamic performance of vertical porous structures under regular waves. China Ocean Engineering, 27(4), pp.451-468.

Levesque, R., 2006. SPSS Inc.(2006). SPSS programming and data management, 3rd edition. SPSS institute. USA.

Lin, P. \& Karunarathna, S.A., 2007. Numerical study of solitary wave interaction with porous breakwaters. Journal of Waterway, Port, Coastal, and Ocean Engineering, 133(5), pp.352-363.

Mallayachari, V. \& Sundar, V., 1994. Reflection characteristics of permeable seawalls. Coastal Engineering, 23(1), pp.135150.

Neelamani, S. \& Sandhya, N., 2005. Surface roughness effect of vertical and sloped seawalls in incident random wave fields. Ocean engineering, 32(3), pp.395-416.
Neelamani, S. \& Sandhya, N., 2003. Wave reflection characteristics of plane, dentated and serrated seawalls. Ocean engineering, 30(12), pp.1507-1533.

Reddy, M.S. \& Neelamani, S., 1992. Wave transmission and reflection characteristics of a partially immersed rigid vertical barrier. Ocean engineering, 19(3), pp.313-325.

Theocharis, I. et al., 2011. A new wave absorbing quay-wall for wave height reduction in a harbor basin. Ocean Engineering, 38(17), pp.1967-1978.

Twu, S.-W. \& Liu, C.-C., 1999. The reflection coefficient of sloping walls. Ocean engineering, 26(11), pp.1085-1094.

Zanuttigh, B. \& van der Meer, J.W., 2008. Wave reflection from coastal structures in design conditions. Coastal engineering, 55(10), pp.771-779. 